\title{
АНАЛИЗ КЛИНИЧЕСКИХ И СОЦИАЛЬНО-ПСИХОЛОГИЧЕСКИХ ФАКТОРОВ, ОПРЕДЕЛЯЮЩИХ ТЯЖЕСТЬ СУИЦИДАЛЬНОГО ПОВЕДЕНИЯ, ПРИВОДЯЩЕГО К СОЧЕТАННОЙ ТРАВМЕ (ПО МАТЕРИАЛАМ МНОГОПРОФИЛЬНОГО СТАЦИОНАРА)
}

\section{ANALYSIS OF CLINICAL AND SOCIO-PSYCHOLOGICAL FACTORS DETERMINING THE SEVERITY OF SUICIDAL BEHAVIOR LEADING TO COMBINED TRAUMA \\ (BASED ON THE MATERIALS OF A MULTIDISCIPLINARY HOSPITAL)}

\section{A. Sinenchenko A. Krasnov \\ G. Sinenchenko}

Summary. The assessment of mental disorders in victims with combined trauma as a result of suicidal behavior who were treated in the department of combined Trauma of the Dzhanelidze Emergency Medicine Research Institute was carried out. It was found that among the victims with combined trauma as a result of suicidal behavior, patients with reactions to severe stress and adaptation disorders prevailed $-47.3 \%$, mental and behavioral disorders due to alcohol consumption $-21.3 \%$, affective mood disorders $-17.3 \%$. In the victims with affective mood disorders, the traumatic illness was of the most severe nature.

Keywords: general hospital, mental disorders, suicide, polytrauma.
Синенченко Андрей Георгиевич

К.м.н., Научно-исследовательский институт скорой помощи имени И.И. Джанелидзе,

Санкт-Петербург

andreysin2013@yandex.ru;

Краснов Алексей Александрович

Д.м.н., дочент, Военно-медицинская академия им. С.М. Кирова, Санкт-Петербург dr.krasnov_28@mail.ru;

Синенченко Георгий Иванович

Д.м.н., профессор, Заслуженный врач РФ, Военномедицинская академия им. С.М. Кирова, Санкт-

Петербург

andreysin2013@yandex.ru;

Аннотачия. Проведена оценка психических расстройств у пострадавших с сочетанной травмой в результате суицидального поведения, проходивших лечение в отделение сочетанной травмы Научно-исследовательского института скорой помощи имени И.И. Джанелидзе. Установлено, что среди пострадавших с сочетанной травмой в результате суицидального поведения преобладали больные с реакциями на тяжелый стресс и расстройствами адаптации - 47,3\%, психическими и поведенческими расстройствами вследствие употребления алкоголя - 21,3\%, аффективными расстройствами настроения - 17,3\%. У пострадавших с аффективными расстройствами настроения, травматическая болезнь носила наиболее тяжелый характер.

Ключевые слова: многопрофильный стационар, психические расстройства, суицид, сочетанная травма.

казатели распространенности суицидальных попыток связаны с злоупотреблением алкоголем и употреблением современных психоактивных веществ (ПАВ) с наркотическим эффектом, доступность огнестрельного оружия [7-10]. Известно, что основанная часть завершенных суицидов осуществляется лицами, страдающими психическими и поведенческими расстройствами [11-13]. По сведениям западных исследователей, от завершённых суицидов погибает от 4 до 10\% лиц, страдающих расстройством личности, а к наиболее общепризнанным факторам суицидального риска у данной категории больных относятся выраженная импульсивность в поведении, перенесенные в детстве физическое и сексуальное насилие [14]. 
Таблица 1. Социально-демографические характеристики пострадавших с СТ в результате суицидального поведения

\begin{tabular}{|c|c|c|c|}
\hline $\begin{array}{l}\text { № } \\
\text { п/п }\end{array}$ & \multicolumn{2}{|c|}{ Параметры } & $\begin{array}{l}\text { Показатели } \\
\text { (n=150) }\end{array}$ \\
\hline \multirow{2}{*}{1} & \multirow{2}{*}{ Пол } & мужчин, абс,\% & $106(70,6 \%)$ \\
\hline & & женщин, абс,\% & $44(29,4 \%)$ \\
\hline 2 & \multicolumn{2}{|c|}{ Возраст на момент госпитализации, лет, $\mathrm{M} \pm \mathrm{Sd}$} & $29,5 \pm 1,6$ \\
\hline 3 & \multicolumn{2}{|c|}{ Не имеющие постоянного места работы, абс,\% } & $113(75,3 \%)$ \\
\hline 4 & \multicolumn{2}{|c|}{ Не состоящие в браке, абс,\% } & $102(68 \%)$ \\
\hline 9 & \multicolumn{2}{|c|}{ Учет у нарколога наркологического диспансера, лечение в наркологических стационарах, абс,\% } & $17(11,3 \%)$ \\
\hline 10 & \multicolumn{2}{|c|}{$\begin{array}{l}\text { Учет у психиатра психоневрологического диспансера, лечение в психиатрических стационарах, } \\
\text { абс,\% }\end{array}$} & $7(4,6 \%)$ \\
\hline 11 & \multicolumn{2}{|c|}{ Суицидальная попытка в анамнезе, абс,\% } & $54(36 \%)$ \\
\hline 12 & \multicolumn{2}{|c|}{ Воспитание в неполных семьях, абс,\% } & $37(24,6 \%)$ \\
\hline 13 & \multicolumn{2}{|c|}{ В анамнезе суицидальные попытки у ближайших родственников, абс,\% } & $32(21,3 \%)$ \\
\hline
\end{tabular}

Таблица 2. Структура психических расстройств у пострадавших с СТ в результате суицидального поведения

\begin{tabular}{|l|l|l|l|}
\hline № $\mathbf{n} / \mathbf{n}$ & Диагноз (МКБ-10) & Частота встречаемости \\
\hline 1 & Шисс. & \% \\
\hline 2 & Аффективные расстройства настроения (F31, F32, F33) & 21 & 14,0 \\
\hline 3 & Реакция на тяжелый стресс и нарушения адаптации (F43, F43.2) & 26 & 17,3 \\
\hline 4 & Психические и поведенческие расстройства вследствие употребления ПАВ (F10-19) & 71 & 47,3 \\
\hline 5 & ВСЕГО & 32 & 21,3 \\
\hline
\end{tabular}

В настоящее время объективная оценка, отражающая сведения об особенностях психических расстройств у лиц с СТ в результате суицидального поведения, необходима для разработки эффективных методов профилактики самоубийств, что и определяет актуальность исследования.

\section{Цель исслеАования}

Провести оценку клинических и социально-психологических факторов, определяющих тяжесть суицидального поведения, приводящего к СТ.

\section{Материалы и методы исследования}

Обследовано 150 пострадавших в возрасте от 18 до 60 лет с СТ в результате суицидального поведения, проходивших лечение в отделении сочетанной травмы (ОСТ). Тяжесть повреждений оценивалось хирургами по шкале Injuru Severity Score (ISS). Диагноз психических расстройств устанавливали в соответствии с критериями Международной классификации болезней 10 пересмотра (WHO, 1992). Статистическую обработку полученных результатов осуществляли в программе Statistica for Windows (версия 10). Качественные признаки сравнивали с помощью критерия Пирсона Хи-квадрат $\left(X^{2}\right)$ с поправкой на непрерывность. Различия в группах сравнения считались статистически значимыми при $\mathrm{p} \leq 0.05$.

\section{Результаты \\ и обсужАения}

Социально-демографические характеристики пострадавших с СТ в результате суицидального поведения представлены в таблице 1.

В результате проведенной работы установили, что в 70,6\% случаях в ОСТ госпитализировались лица мужского пола $\left(n=106, p=0,2^{*} 10^{-4}\right)$, не имеющие постоянного места работы (75,3\%), не состоящие в браке (68\%). Суицидальная попытка оценивалась как повторная в $36 \%$ случаях, состояли на учете у психиатра - 4,6\%, нарколога - 11,3\% пострадавших. Средний возраст больных составил $29,5 \pm 1,6$ лет.

Структура психических расстройств у пострадавших с СТ в результате суицидального поведения представлена в таблице 2 . 
Как видно из представленных в таблице 2 данных, среди пострадавших СТ в результате суицидального поведения большую часть составили больные с реакциями на тяжелый стресс и расстройствами адаптации - 47,3\%, психическими и поведенческими расстройствами вследствие употребления ПАВ - 21,3\%, аффективными расстройствами настроения - 17,3\%.

Следует отметить, что депрессивная симптоматика при расстройствах невротического уровня имела реактивный характер, пролонгированное течением, формировалась у личностей аффективного склада, в ответ на психотравмирующую ситуацию, часто связанную с разрывом значимых отношений с лицом противоположного пола или с конфликтными отношениями с родственниками, воспринимаемыми больным как «акт несправедливого отношения». По мере нарастания интенсивности депрессивной симптоматики у больного формировалась стойкая «суицидальная доминанта» с отрицательной оценкой своего прошлого, настоящего и будущего, чувством бесперспективности, мыслями о самоубийстве, носящими сверхценный характер, воспринимаемыми больным как «единственный выход из сложившейся ситуации».

У пострадавших с психическими и поведенческими расстройствами вследствие употребления ПАВ, преобладали лица с зависимостью от алкоголя - 75\% (24). Суицидальные действия совершались в абстинентном периоде, который сопровождался аффективными нарушениями депрессивного характера с идей самообвинения, фиксацией на психотравмирующих ситуациях, связанных с конфликтом в сфере значимых потребностей.

При аффективных расстройствах суицидальное поведение напрямую было связано с выраженностью депрессивных переживаний. Суицидальные поступки носили импульсивный характер и отличались особой брутальностью. У данной категории больных травматическая болезнь имела наиболее неблагоприятный прогноз, по причине формирования тяжелых повреждений головного и спинного мозга, конечностей и внутренних органов.
У пострадавших, страдающих шизофренией и бредовыми расстройствами мотивом самоубийств явились переживания, обусловленные содержанием психоза. Клиническая картина содержала разнообразные продуктивные психопатологические синдромы (параноидные, депрессивно-параноидные), включающие конфликтогенные моменты.

СТ, чаще возникали в результате суицида способом падения с высоты (61,3\%), (92, p=0.001), реже способом падения под движущийся транспорт -34,6\% (52). Другие способы лишения себя жизни (использование огнестрельного оружия, режущих предметов и т.д.) встречались значительно реже - в 4,1\% (6) случаях.

Таким образом, исследование показало, что у больных с эндогенным характером заболевания риск суицидального поведения зависел от болезненных симптомов и от конфликтогенных факторов. У лиц с пограничной психической патологией обнаруживались объективные и субъективные признаки социально-психологической дезадаптации ведущей к суициду. Полученные данные находят свое подтверждение в ранее проведенных исследованиях $[15,16]$. В свою очередь, показано, что злоупотребление алкоголем приводит к депрессии, формирует дезадаптирующие суицидоопасные позиции, увеличивает риск суицидального поведения [17].

\section{Зак^ючение}

Приведенные данные исследования свидетельствуют о том, что у большинства пострадавших с СТ в результате суицидального поведения диагностируются признаки социально-психологической дезадаптации, клинически выражающиеся депрессивным характером переживаний. Провоцирующим фактором в формировании у пострадавших суицидоопасных позиций явилось употребление алкоголя. Наиболее тяжелый характер травм диагностировали у лиц с аффективными расстройствами настроения, по причине того, что суицидальные поступки отличались особой брутальностью.

\section{ЛИТЕРАТУРА}

1. Jouda M., Finn Y. Training in polytrauma management in medical curricula: A scoping review. Med Teach. 2020;42(12):1385-1393. doi: 10.1080/0142159X.2020.1811845

2. Marsden N.J, Tuma F. Polytraumatized Patient. 2021 Jul 5. In: StatPearls [Internet]. Treasure Island (FL): StatPearls Publishing; 2021 Jan-. PMID: 32119313.

3. Cassone M., Vollmer T., Factor M., Sallade T.D. Polytrauma from a North American Black Bear Attack. Wilderness Environ Med. 2020;31(4):457-461. doi: 10.1016/j.wem.2020.06.006.

4. Brulin-Solignac D., Le Bihan P., Bouchard J.P. Suicides avec pactes suicidaires [Suicides with suicide pacts]. Rev Infirm. 2021;70(270):22-23. doi: 10.1016/j. revinf.2021.02.008.

5. Jollant F. Clinique de la crise suicidaire [Clinic of suicidal crisis]. Rev Infirm. 2021;70(270):16-19. doi: 10.1016/j.revinf.2021.02.006. 
6. Quillerou B., Bouchard J.P. Épidémiologie du suicide et de ses tentatives [Epidemiology of suicide and suicide attempts]. Rev Infirm. 2021;70(270):20-21. French. doi: 10.1016/j.revinf.2021.02.007.

7. SnowdonJ.,Choi N.G. Undercounting ofsuicides:Wheresuicidedataliehidden.GlobPublicHealth.2020;15(12):1894-1901.doi:10.1080/17441692.2020.1801789.

8. Бабанин А.А., Уланов В.С. Анализ смертельных отравлений психоактивными веществами в Республике Крым за 1993-2017 гг. Судебно-медицинская экспертиза. 2019;62(5):54-57

9. Синенченко А.Г., Лодягин А.Н., Батоцыренов Б.В., Балабанова 0.Л. Эпидемиология острых отравлений гамма-гидроксимасляной кислотой в санкт-петербурге (по данным многопрофильного стационара). Токсикологический вестник. 2021;2:34-40.

10. Лях А.О. Характеристика причин совершения преступлений в сфере незаконного оборота новых потенциально опасных психоактивных веществ. Студенческий форум. 2019;5(56):73-76

11. Разводовский Ю.Е. Потребление крепкого алкоголя и суициды в России. Академический журнал Западной Сибири. 2021;1(90):14-16

12. Петрова Н.Н. Факторы риска и превенция суицида при шизофрении: фокус на роли современных инъекционных антипсихотиков-пролонгов. Современная терапия психических расстройств. 2021;3:31-37 D0I: 10.21265/PSYPH.2021.15.71.003

13. Вельтищев Д.Ю., Ковалевская 0.Б., Серавина 0.Ф. Факторы риска и профилактика рекуррентности депрессии. Журнал неврологии и психиатрии им. С.С. Корсакова. 2017;117(6):120-125 D01: 10.17116/jnevro201711761120-125

14. Васильев В.В., Искандерова Р.Э. Суицидальное поведение при пограничном расстройстве личности: современное состояние проблемы. Российский психиатрический журнал.2021;3:45-55 D0I: 10.47877/1560-957X-2021-10305

15. Винникова И.Н., Дмитриев А.С., Положий Б.С., Печенкина 0.И., Ермолаева Д.Ю. Суицидальное поведение как фактор риска социальной опасности пациентов с расстройствами шизофренического спектра. 2019;4(37):76-84. D0I: 10.32878/suiciderus.19-10-04(37)-76-84

16. Рутковская Н.С., Шамрей В.К., Курасов Е.С., Колчев А.И., Нечипоренко В.В. Особенности раннего постсуицидального периода у лиц с психическими расстройствами после повторных суицидальных попыток. ДОКТОР. РУ.2020;19(9):59-64

17. Шалагин А.Е., Идиятуллов А.Д. Сопряженность аддиктивного поведения и суицидальных рисков. Ученые записки Казанского юридического института МВД России. 2019;4(7):26-33.

(с) Синенченко Андрей Георгиевич ( andreysin2013@yandex.ru),

Краснов Алексей Александрович (dr.krasnov_28@mail.ru ), Синенченко Георгий Иванович ( andreysin2013@yandex.ru ).

Журнал «Современная наука: актуальные проблемы теории и практики»

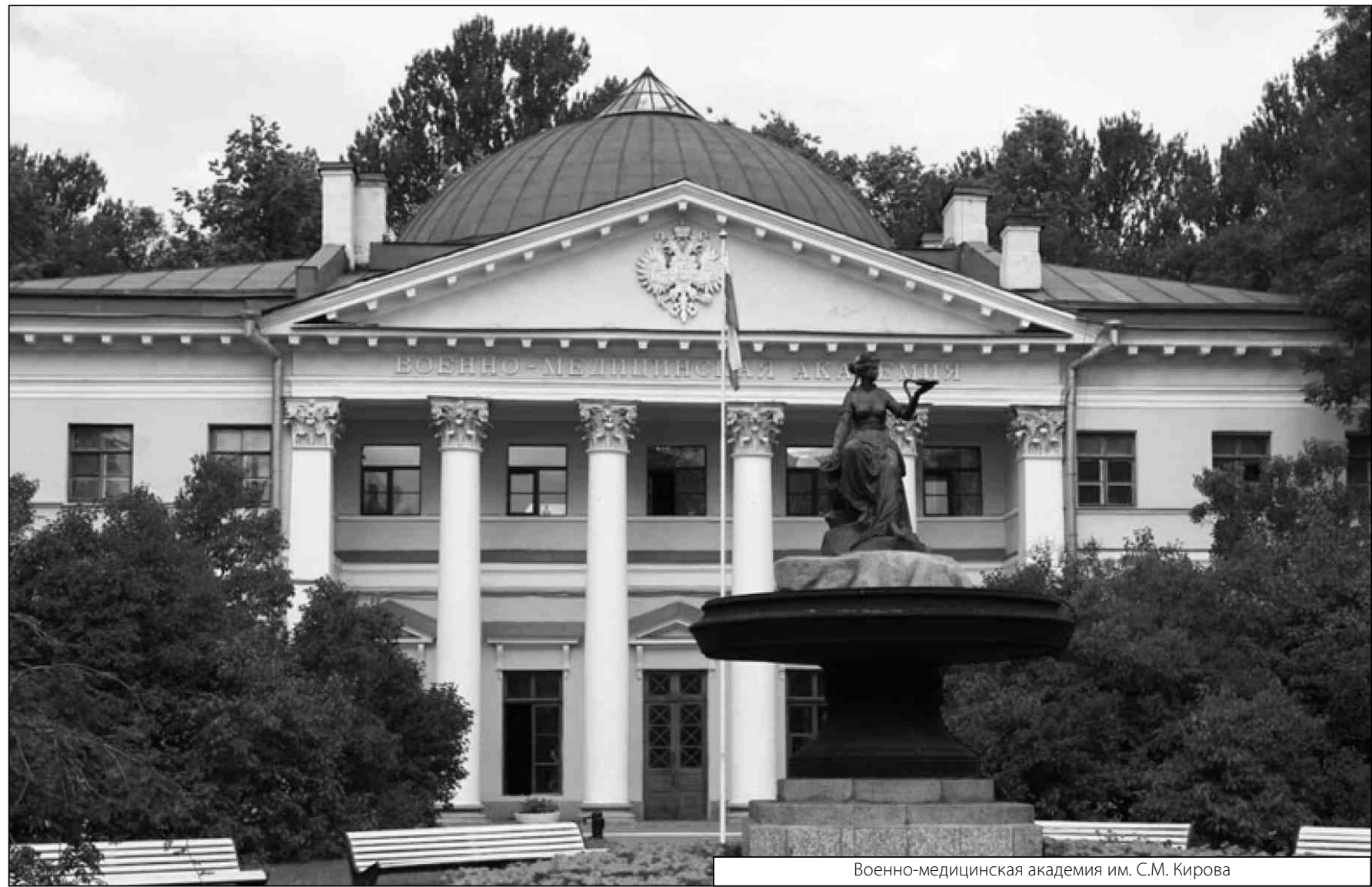

